\title{
Comparison of stresses in monoblock tilted implants and conventional angled multiunit abutment-implant connection systems in the all-on-four procedure
}

Özge Özdal Zincir ${ }^{1 *}$ (1) and Ateş Parlar²

\begin{abstract}
Background: The All-on-four dental implant method is an implantology method designed to provide a comfortable prosthetic treatment option by avoiding advanced surgical procedures. This research aims to compare and evaluate the stress and tension values in conventional angled multiunit abutment-implant connection systems and monoblock dental implants used in the all-on-four procedure with finite element analysis.

Methods: Two master models were created by placing four implants connected to multiunit abutments (group A) in the interforaminal region of a completely edentulous mandible and four monoblock implants (group B) in the same region of another completely edentulous mandible. Group A implants were classified according to their diameter as follows: $3.5 \mathrm{~mm}$ (M1A), $4.0 \mathrm{~mm}$ (M2A), and $4.5 \mathrm{~mm}$ (M3A). Similarly, group B implants were classified as M1B, M2B, and $\mathrm{M} 3 \mathrm{~B}$. In the six models rehabilitated with acrylic fixed prostheses, a $100 \mathrm{~N}$ force was applied to the anterior implant region, and a $250 \mathrm{~N}$ force was applied to the posterior cantilever in both axial and $30^{\circ}$ oblique directions. Von Mises stresses were analyzed in the bone and implant regions of all models.
\end{abstract}

Results: M1A and M1B, M2A and M2B, and M3A and M3B were compared with each other under axial and oblique forces. The maximum Von Mises stresses in the bone around implants and the prosthesis screws, and the maximum and minimum principal stresses in the cortical and trabecular bone in group A models were significantly higher than those in group B models.

Conclusions: In monoblock implant systems under axial and oblique forces, higher stress is accumulated in the bone, prosthesis screw and implant compared to multiunit abutment-implant connection systems.

Keywords: All-on-four, Finite element analysis, Fixed prosthesis, Monoblock implant, Tilted implant

\section{Background}

Dental implant-supported restorations are preferred over complete dentures as they provide edentulous patients with a more comfortable treatment option. Moreover,

*Correspondence: ozgeozdalzincir@gmail.com

1 Department of Oral and Maxillofacial Surgery, Faculty of Dentistry, Istanbul Gelisim University, Istanbul, Turkey

Full list of author information is available at the end of the article they can counter problems such as retention failure, lack of stability, and patient dissatisfaction associated with complete dentures [1]. However, there are some limiting factors in dental implant surgery, especially in edentulous patients. These factors include poor bone quality in the posterior jaw region, decreased alveolar bone volume, and enlargement of the lower wall of the maxillary sinus towards the alveolar ridge [2, 3]. Advanced surgical practices and graft materials are required to eliminate 
these limitations, thus increasing the duration and cost of treatment [4].

Eliasson et al. [5] suggested that four implants can be distributed between the mental foramina to receive fixed restorations in edentulous patients. However, a limited bone volume between the mental foramina necessitates the fabrication of prostheses with long-span cantilevered segments distal to posterior implants. Moreover, the presence of cantilevers in fixed restorations can augment the load on implants up to two or three times due to bending moments. Some alternatives have been proposed to overcome these limitations, such as placing a short implant distal to the mental foramina and combining the cantilever segment with these implants [6].

Malo et al. [7] developed the All-on-four treatment protocol (Nobel BioCare AG, Kloten, Switzerland) based on the immediate loading of four dental implants placed between the mental foramina. In the All-on-four system, two anterior implants are placed straight and parallel to each other, and two posterior implants are tilted distally to a maximum of $45^{\circ}$. This procedure decreases the cantilever length and the risk of stress accumulation and bone resorption at the implant-bone interface [7].

Angled multiunit abutments are used for tilted distal implants in the traditional All-on-four procedure. Microorganisms and other toxic substances can accumulate in the microspaces between the multiunit abutment and the implant body, increasing the risk of peri-implantitis [8, 9]. Moreover, screw fractures that result from abutment screw loosening are among multiunit abutment complications [10].

Monoblock tilted dental implant system is a one-piece system that does not have any components such as abutment screws between the implant and abutment. It has been used as an alternate to the multiunit abutmentimplant connection system in the All-on-four procedure recently.

In the biomechanical analysis of dental implants, the finite elemet method (FEM) is frequently used because it reflects the complexity of clinical conditions and has benefits over many analysis methods [11]. The purpose of this study is to compare the stress and strain values of the monoblock tilted dental implant system with the conventional angled multiunit abutment-implant connection system in the implant parts and surrounding bone using FEM.

\section{Methods}

Four implants of the multiunit abutment-implant connection system (Oxy Implant by Biomec S.r.l, Colico, Italy) [group A] and four monoblock implants (Oxy Implant by Biomec S.r.l, Colico, Italy) [group B] were installed in the interforaminal area of the edentulous

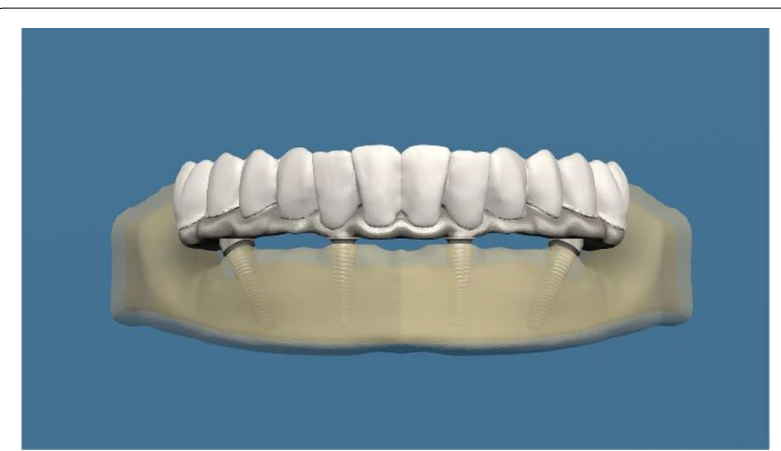

Fig. 1 Finite element model of all-on-four procedure with implants of the multiunit abutment-implant connection system

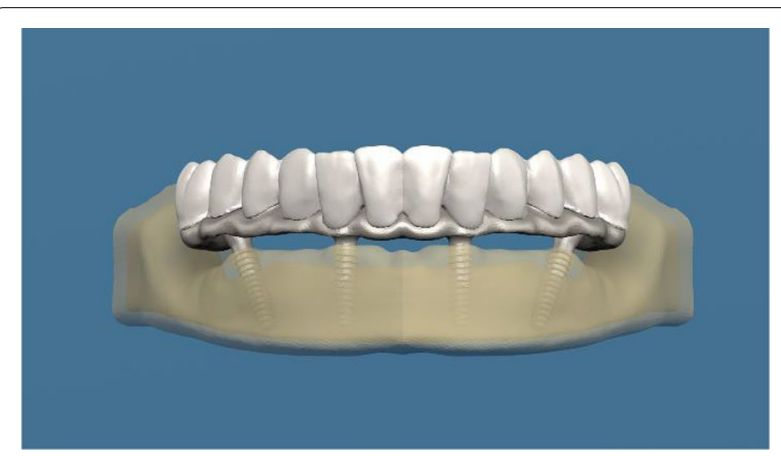

Fig. 2 Finite element model of all-on-four procedure with implants of the monoblock implant system

mandible, and two different 3-D finite element models were prepared and rehabilitated with an acrylic fixed prosthesis. The anterior implants used in the models were placed straight, and the posterior implants at $30^{\circ}$ angles (Figs. 1 and 2). A total of 6 models were obtained from each system using implants with $3.5 \mathrm{~mm}, 4.0 \mathrm{~mm}$, and $4.5 \mathrm{~mm}$ diameters.

Dental volumetric tomography of the edentulous mandible was used to get finite element models. To optimize the 3-dimension (3-D) network structure and make it more homogeneous, generate the 3-D solid model, and the FEM analysis; Intel Xeon ${ }^{\circledR} \mathrm{R}$ CPU $3.30 \mathrm{GHz}$ processor, 500 GB Hard disk, a computer equipped with 14 GB RAM and Windows 7 Ultimate Version Service Pack 1 operating system, Activity 880 (smart optics Sensortechnik $\mathrm{GmbH}$, Bochum, Germany), an optical scanner and 3-D scanner, Rhinoceros 4.0 (Seattle, WA 98103 USA), 3-D modeling software, VRMesh Studio (VirtualGrid Inc, Bellevue City, WA, USA), and Algor Fempro (ALGOR, Inc., PA 152382932 USA) analysis program were used to model cortical bone, trabecular bone, body of implant, abutment, and prosthetic materials.

All the materials used in the program and models were considered linear elastic, homogeneous, and isotropic. 
As the biological properties of the materials used in the models do not have accepted universal values, the average values were obtained from the literature (Table 1).

\section{Bone}

The edentulous mandible bone was modeled with a height of $15 \mathrm{~mm}$, a thickness of $7 \mathrm{~mm}$, and an interforamina range of $46 \mathrm{~mm}$. The cortical bone heights in the upper and lower layers of the model were $3 \mathrm{~mm}$ and $2 \mathrm{~mm}$, respectively. The trabecular bone height modeled between the two cortical layers was $10 \mathrm{~mm}$.

\section{Dental implants and abutments}

In the multiunit abutment-implant connection system groups, conical connection implants with $3.5 \mathrm{~mm}$, $4.0 \mathrm{~mm}, 4.5 \mathrm{~mm}$ diameters, and $11.5 \mathrm{~mm}$ length were used in the anterior area. The same diameter implants with $13 \mathrm{~mm}$ length were used in the posterior region. Also, $30^{\circ}$ angulated multiunit abutments were used for tilted posterior implants, and straight multiunit abutments were used for anterior implants.

In the monoblock implant system groups, straight monoblock implants with $3.5 \mathrm{~mm}, 4.0 \mathrm{~mm}, 4.5 \mathrm{~mm}$ diameters, and $11.5 \mathrm{~mm}$ length were used in the anterior region. Monoblock implants with the same implant diameters, $13 \mathrm{~mm}$ length, and a $30^{\circ}$ tilt were used in the posterior area.

Implants in the anterior area were installed as far as possible from each other, with a confident distance of $12 \mathrm{~mm}$ between implants in the posterior region.

\section{Prosthesis}

A minimum total prosthesis thickness of $1.5 \mathrm{~mm}$ is suggested for resistance to fracture [12]. In this study, a $2.2 \mathrm{~mm}$ thick homogeneous acrylic resin block with a $10 \mathrm{~mm}$ cantilever on both ends and a titanium substructure was created.

Table 1 Properties of materials in models

\begin{tabular}{lcl}
\hline & $\begin{array}{l}\text { Modulus of } \\
\text { elasticity (GPa) }\end{array}$ & Poisson's ratio \\
\hline Acrylic resin (prosthesis) & 2.7 & 0.35 \\
Cortical bone & 13.0 & 0.3 \\
Trabecular bone & 5.5 & 0.3 \\
$\begin{array}{l}\text { Titanium implant and abut- } \\
\text { ment (Grade 4 titanium) }\end{array}$ & 102.0 & 0.35 \\
$\begin{array}{l}\text { Titanium substructure in pros- } \\
\text { thesis (Ti-6Al-4V) }\end{array}$ & 110.0 & 0.28 \\
\hline
\end{tabular}

\section{Loading procedure}

A $100 \mathrm{~N}$ force was carried out to the anterior implants, and a $250 \mathrm{~N}$ force was carried out to the mesiobuccal and distobuccal ends of the cantilever in the posterior region (Fig. 3). Both axial and oblique forces angled at $30^{\circ}$ to the long axis were applied to the force zones in each model.

\section{Meshed models}

These finite element analysis models were transferred to Algor Fempro (Algor Inc., USA) software in STL format for analysis. They were created geometrically using VRMesh software for meshing (Fig. 4).

In the meshing process, models were made of 10 node (brick type) elements as far as possible. In the regions close to the center, fewer nodes were used to complete the structure when necessary. The models were converted into solid bricks and tetrahedral elements. In bricks and tetrahedral modeling, Fempro uses 8-noded

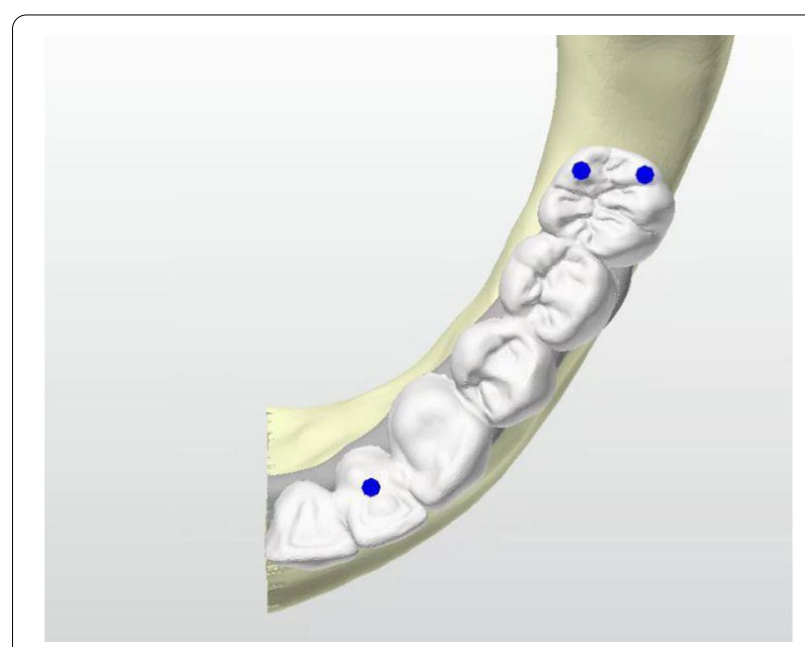

Fig. 3 Force applied zones in models

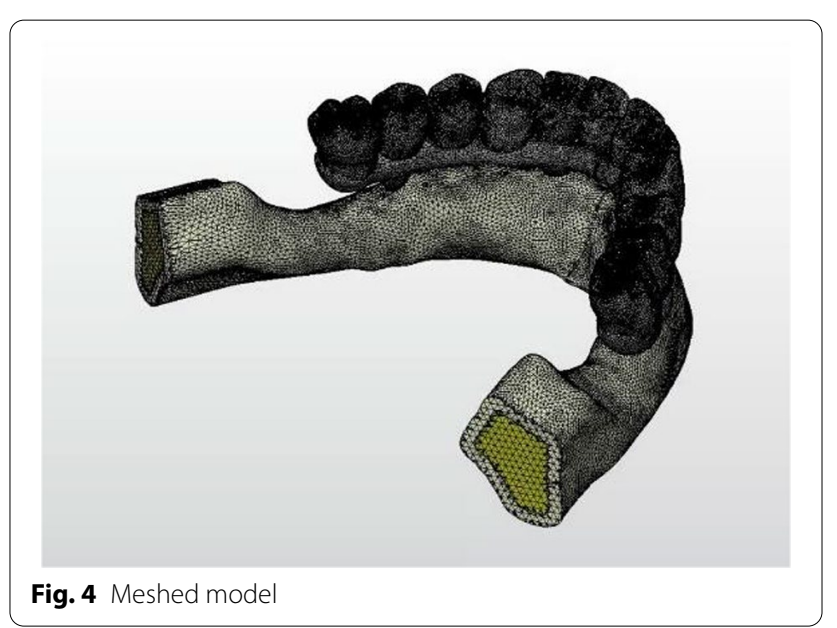


elements as much as it can and 7-node, 6-node, 5-node, and 4-node elements where 8-node elements cannot reach the required details. To obtain realistic results, considering the dimensions of the mandible bone model, we selected as many elements as possible. A total of six mathematical models were created with implants of different diameters and categorized into two main groups: the multiunit abutment-implant connection implants group (group A) and the monoblock implants group (group B). Group A implants were classified according to their diameter as follows: $3.5 \mathrm{~mm}$ (model-1A [M1A]), $4.0 \mathrm{~mm}$ (model-2A [M2A]), and $4.5 \mathrm{~mm}$ (model-3A [M3A]). Group B implants were classified as follows: $3.5 \mathrm{~mm}$ (model-1B [M1B]), $4.0 \mathrm{~mm}$ (model-2B [M2B]), and $4.5 \mathrm{~mm}$ (model-3B [M3B]). The number of elements and knots used in the created mathematical models are presented in Table 2 .

\section{Comparative groups}

The stress rates in the implants and prosthesis screws of the same diameter in the same area were compared to the stress rates in the bone under axial and oblique loading. The determined forces were applied to the force regions of the six models concurrently.

\section{Measurements of stress and strain values}

In loadings using the FEM program, von Mises standard were used to assess the tension in the implants and prosthesis screws, and maximum principal stresses were

Table 2 Number of nodes and number of elements in models

\begin{tabular}{lll}
\hline $\begin{array}{l}\text { Models in } \\
\text { groups }\end{array}$ & Number of nodes & Number of elements \\
\hline M1A & 281,407 & $1,329,234$ \\
M2A & 261,731 & $1,286,671$ \\
M3A & 266,199 & $1,313,308$ \\
M1B & 320,877 & $1,317,592$ \\
M2B & 314,863 & $1,357,176$ \\
M3B & 320,458 & $1,396,542$ \\
\hline
\end{tabular}

used to evaluate the tension in the cortical and trabecular bone.

\section{Results}

The maximum von Mises stress (VMS) (MPa) values in the implants and prosthesis screws and the minimummaximum principal stress (PS) $(\mathrm{MPa})$ values in the cortical and trabecular bone are shown in Tables 3, 4, 5 and 6, and their distribution is shown in Figs. 5, 6, 7, 8, 9, 10, 11, $12,13,14,15$ and 16.

\section{Assessment of the models \\ Assessment of VMS in implants}

The highest VMS values under axial and oblique loading in both anterior and posterior implants were observed in the M1B model. The lowest VMS values under axial and oblique loading were observed in anterior implants in the M2B model; the lowest VMS values in posterior implants were noted in the M1A model under axial loading and M3A model under oblique loading (Table 3).

\section{Assessment of VMS in prosthesis screws of implants}

In the anterior implant prosthesis screws of the M2B model and posterior implant prosthesis screws of the M3B model, the highest VMS values were observed under both axial and oblique loading. The lowest VMS values were observed in the M3A model in both

Table 4 Maximum VMS in prosthesis screws of implants (MPa)

\begin{tabular}{|c|c|c|c|c|}
\hline \multirow[t]{2}{*}{ Model } & \multicolumn{2}{|l|}{ Axial force } & \multicolumn{2}{|c|}{ Oblique force } \\
\hline & $\begin{array}{l}\text { Anterior } \\
\text { implant's } \\
\text { screw }\end{array}$ & $\begin{array}{l}\text { Posterior } \\
\text { implant's } \\
\text { screw }\end{array}$ & $\begin{array}{l}\text { Anterior } \\
\text { implant's } \\
\text { screw }\end{array}$ & $\begin{array}{l}\text { Posterior } \\
\text { implant's } \\
\text { screw }\end{array}$ \\
\hline M1A & 16.97 & 58.81 & 40.12 & 96.47 \\
\hline $\mathrm{M} 2 \mathrm{~A}$ & 16.70 & 61.50 & 39.76 & 55.06 \\
\hline M3A & 16.39 & 57.74 & 38.56 & 56.05 \\
\hline M1B & 113.23 & 345.10 & 342.16 & 800.37 \\
\hline M2B & 190.81 & 316.80 & 596.84 & 723.70 \\
\hline M3B & 122.13 & 345.82 & 389.60 & 827.17 \\
\hline
\end{tabular}

Table 3 Maximum VMS around implants (MPa)

\begin{tabular}{|c|c|c|c|c|}
\hline \multirow[t]{2}{*}{ Model } & \multicolumn{2}{|l|}{ Axial force } & \multicolumn{2}{|l|}{ Oblique force } \\
\hline & Anterior implant & Posterior implant & Anterior implant & Posterior implant \\
\hline M1A & 64.78 & 143.06 & 255.51 & 555.95 \\
\hline $\mathrm{M} 2 \mathrm{~A}$ & 57.04 & 149.48 & 208.10 & 505.82 \\
\hline M3A & 70.37 & 177.96 & 240.35 & 424.52 \\
\hline M1B & 275.08 & 429.99 & 752.01 & 1025.61 \\
\hline $\mathrm{M} 2 \mathrm{~B}$ & 210.86 & 359.12 & 652.88 & 795.31 \\
\hline M3B & 181.36 & 320.53 & 426.72 & 703.75 \\
\hline
\end{tabular}


Table 5 Maximum-minimum PS in cortical bone (MPa)

\begin{tabular}{|c|c|c|c|c|c|c|c|c|}
\hline \multirow[t]{2}{*}{ Model } & \multicolumn{4}{|l|}{ Axial force } & \multicolumn{4}{|l|}{ Oblique force } \\
\hline & $\begin{array}{l}\text { Maximum } \\
\text { PS cortical } \\
\text { bone around } \\
\text { the anterior } \\
\text { implant }\end{array}$ & $\begin{array}{l}\text { Minimum } \\
\text { PS cortical } \\
\text { bone around } \\
\text { the anterior } \\
\text { implant }\end{array}$ & $\begin{array}{l}\text { Maximum } \\
\text { PS cortical } \\
\text { bone around } \\
\text { the posterior } \\
\text { implant }\end{array}$ & $\begin{array}{l}\text { Minimum } \\
\text { PS cortical } \\
\text { bone around } \\
\text { the posterior } \\
\text { implant }\end{array}$ & $\begin{array}{l}\text { Maximum } \\
\text { PS cortical } \\
\text { bone around } \\
\text { the anterior } \\
\text { implant }\end{array}$ & $\begin{array}{l}\text { Minimum } \\
\text { PS cortical } \\
\text { bone around } \\
\text { the anterior } \\
\text { implant }\end{array}$ & $\begin{array}{l}\text { Maximum } \\
\text { PS cortical } \\
\text { bone around } \\
\text { the posterior } \\
\text { implant }\end{array}$ & $\begin{array}{l}\text { Minimum } \\
\text { PS cortical } \\
\text { bone around } \\
\text { the posterior } \\
\text { implant }\end{array}$ \\
\hline $\mathrm{M} 1 \mathrm{~A}$ & 12.99 & 21.11 & 9.97 & 43.62 & 34.12 & 33.52 & 64.75 & 96.63 \\
\hline $\mathrm{M} 2 \mathrm{~A}$ & 15.71 & 20.58 & 13.41 & 47.55 & 28.21 & 33.50 & 66.15 & 104.18 \\
\hline M3A & 13.72 & 18.54 & 9.79 & 44.78 & 17.43 & 27.40 & 48.17 & 90.95 \\
\hline $\mathrm{M} 1 \mathrm{~B}$ & 34.25 & 40.39 & 25.02 & 155.56 & 115.32 & 125.06 & 154.02 & 277.28 \\
\hline $\mathrm{M} 2 \mathrm{~B}$ & 36.80 & 46.62 & 23.27 & 110.79 & 112.66 & 93.94 & 123.58 & 242.73 \\
\hline M3B & 27.28 & 28.63 & 19.08 & 89.07 & 67.15 & 82.76 & 99.72 & 190.66 \\
\hline
\end{tabular}

Table 6 Maximum-minimum PS in trabecular bone (MPa)

\begin{tabular}{|c|c|c|c|c|c|c|c|c|}
\hline \multirow[t]{2}{*}{ Model } & \multicolumn{4}{|l|}{ Axial force } & \multicolumn{4}{|l|}{ Oblique force } \\
\hline & $\begin{array}{l}\text { Maximum PS } \\
\text { trabecular } \\
\text { bone around } \\
\text { the anterior } \\
\text { implant }\end{array}$ & $\begin{array}{l}\text { Minimum PS } \\
\text { trabecular } \\
\text { bone around } \\
\text { the anterior } \\
\text { implant }\end{array}$ & $\begin{array}{l}\text { Maximum PS } \\
\text { trabecular } \\
\text { bone around } \\
\text { the posterior } \\
\text { implant }\end{array}$ & $\begin{array}{l}\text { Minimum PS } \\
\text { trabecular } \\
\text { bone around } \\
\text { the posterior } \\
\text { implant }\end{array}$ & $\begin{array}{l}\text { Maximum PS } \\
\text { trabecular } \\
\text { bone around } \\
\text { the anterior } \\
\text { implant }\end{array}$ & $\begin{array}{l}\text { Minimum PS } \\
\text { trabecular } \\
\text { bone around } \\
\text { the anterior } \\
\text { implant }\end{array}$ & $\begin{array}{l}\text { Maximum PS } \\
\text { trabecular } \\
\text { bone around } \\
\text { the posterior } \\
\text { implant }\end{array}$ & $\begin{array}{l}\text { Minimum PS } \\
\text { trabecular } \\
\text { bone around } \\
\text { the posterior } \\
\text { implant }\end{array}$ \\
\hline $\mathrm{M} 1 \mathrm{~A}$ & 3.60 & 4.03 & 8.79 & 11.03 & 9.87 & 10.01 & 19.19 & 23.58 \\
\hline $\mathrm{M} 2 \mathrm{~A}$ & 3.35 & 5.16 & 7.15 & 16.10 & 6.89 & 10.30 & 17.19 & 24.49 \\
\hline M3A & 3.39 & 3.64 & 8.95 & 17.63 & 5.74 & 13.52 & 18.27 & 27.67 \\
\hline M1B & 8.44 & 9.31 & 6.71 & 9.90 & 21.58 & 19.20 & 14.00 & 17.04 \\
\hline $\mathrm{M} 2 \mathrm{~B}$ & 5.07 & 5.02 & 7.09 & 10.49 & 10.12 & 17.97 & 14.34 & 22.23 \\
\hline M3B & 12.13 & 5.38 & 25.08 & 12.41 & 8.87 & 12.98 & 23.82 & 37.43 \\
\hline
\end{tabular}

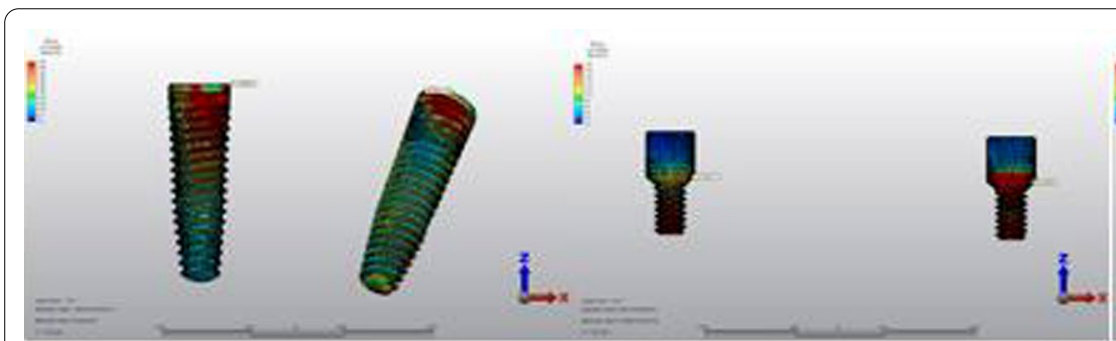

(a)

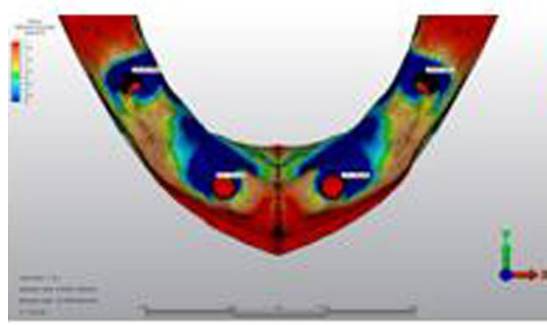

(d) (b)

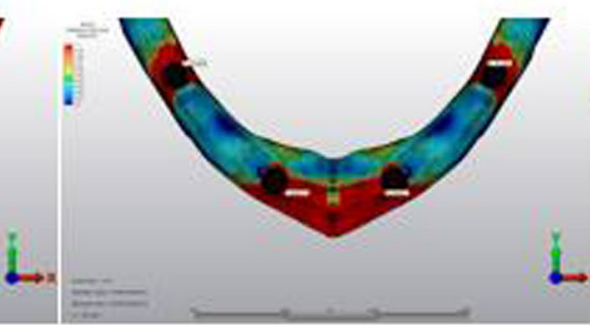

(e)

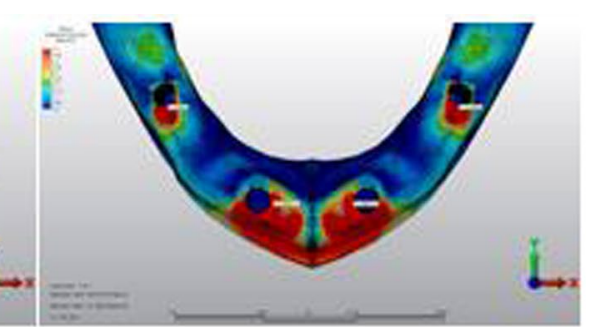

(c)

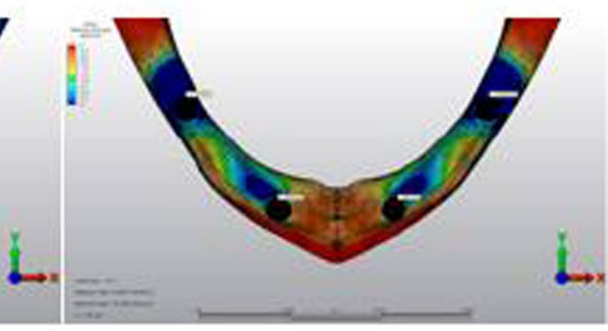

(f)

Fig. 5 Axial loading in M1A. a The maximum VMS around implants; $\mathbf{b}$ the maximum VMS in prosthesis screws of implants; $\mathbf{c}$ maximum PS in cortical bone; $\mathbf{d}$ minimum PS in cortical bone; e maximum PS in trabecular bone; $\mathbf{f}$ minimum PS in trabecular bone 


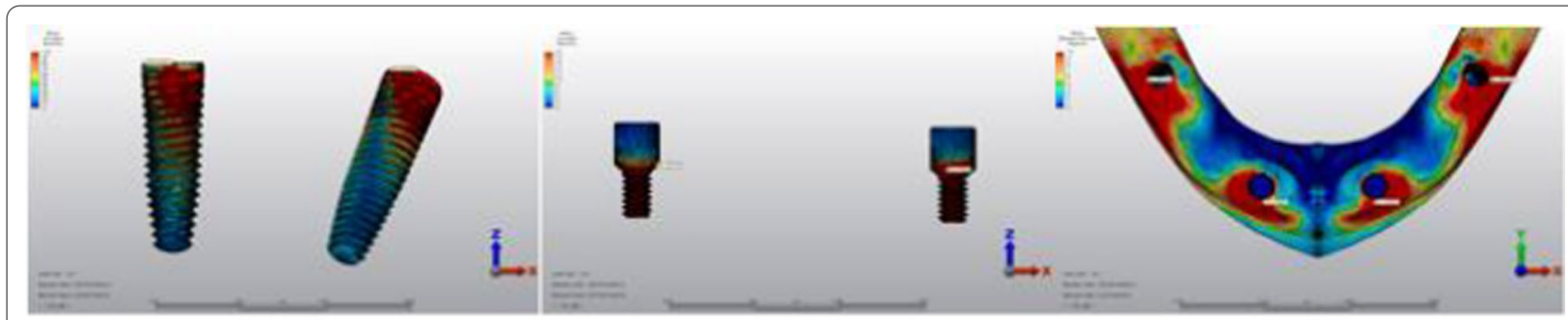

(a)

(b)

(c)

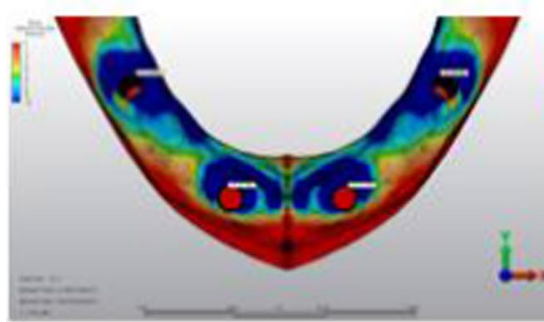

(d)

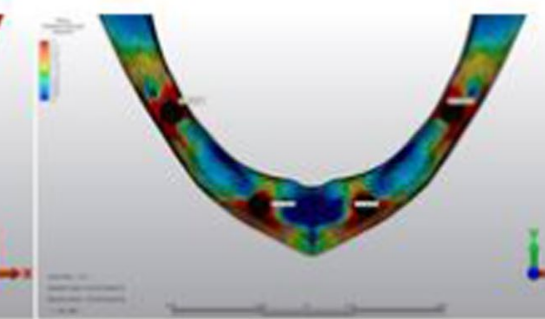

(e)

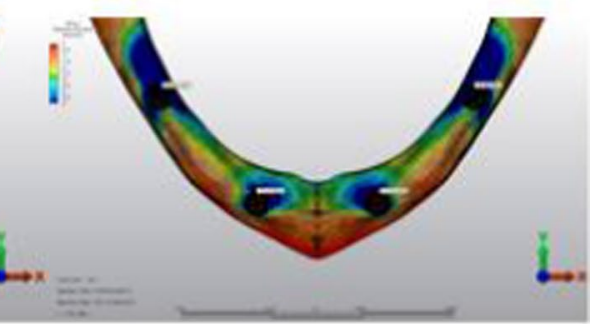

(f)

Fig. 6 Oblique loading in M1A. a The maximum VMS around implants; $\boldsymbol{b}$ the maximum VMS in prosthesis screws of implants; $\mathbf{c}$ maximum PS in cortical bone; $\mathbf{d}$ minimum PS in cortical bone; e maximum PS in trabecular bone; $\mathbf{f}$ minimum PS in trabecular bone

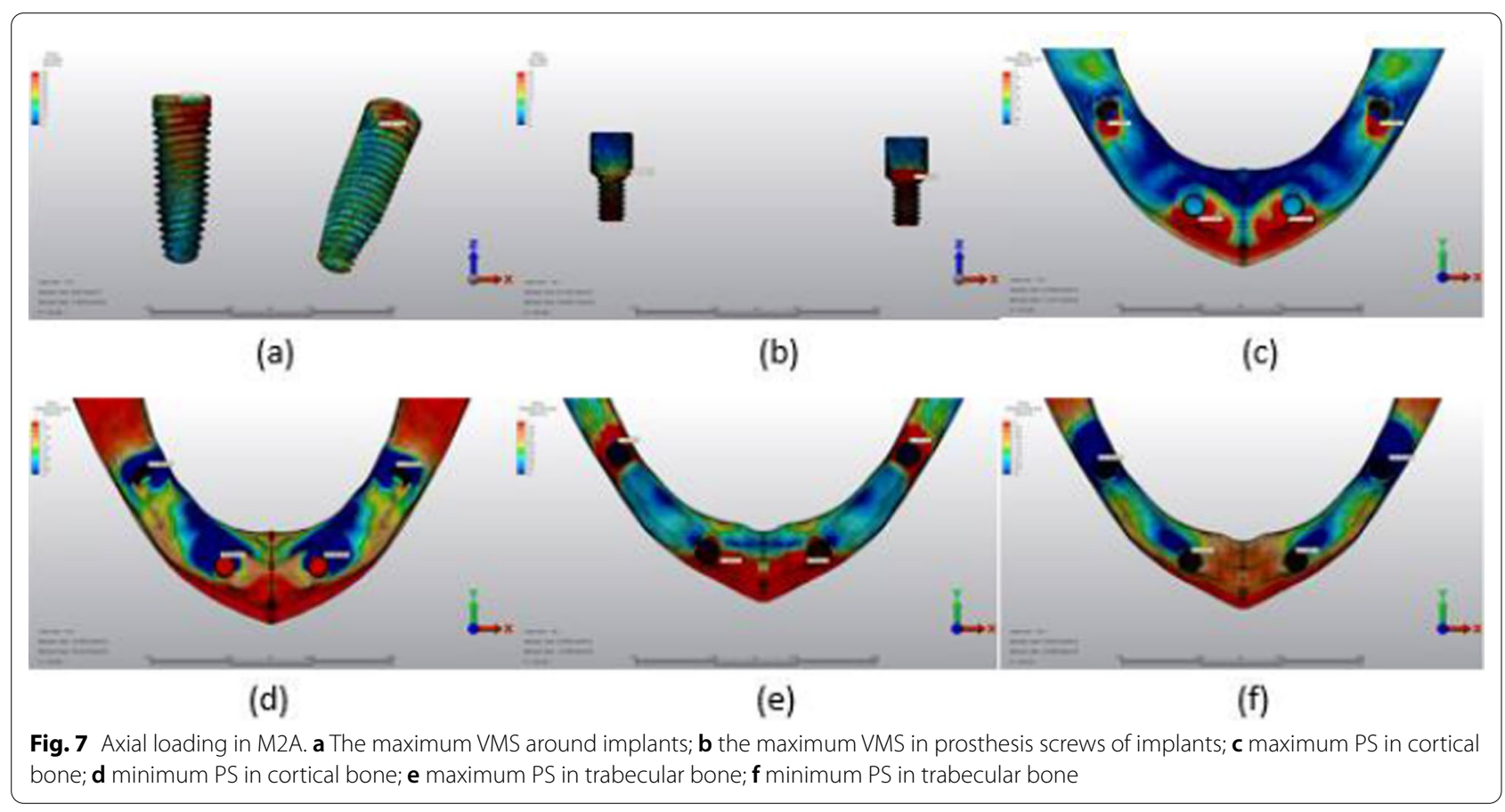

anterior and posterior implant prosthesis screws under axial loading; the lowest VMS values under oblique loading were observed in the M3A model in anterior implant prosthesis screws and the M2A model in posterior implant prosthesis screws (Table 4).

\section{Assessment of maximum-minimum PS rates in cortical bone}

The highest maximum and minimum PS values in the cortical bone around anterior implants were observed in the M2B model, and around posterior implants in the M1B model under axial loading. The highest maximum 

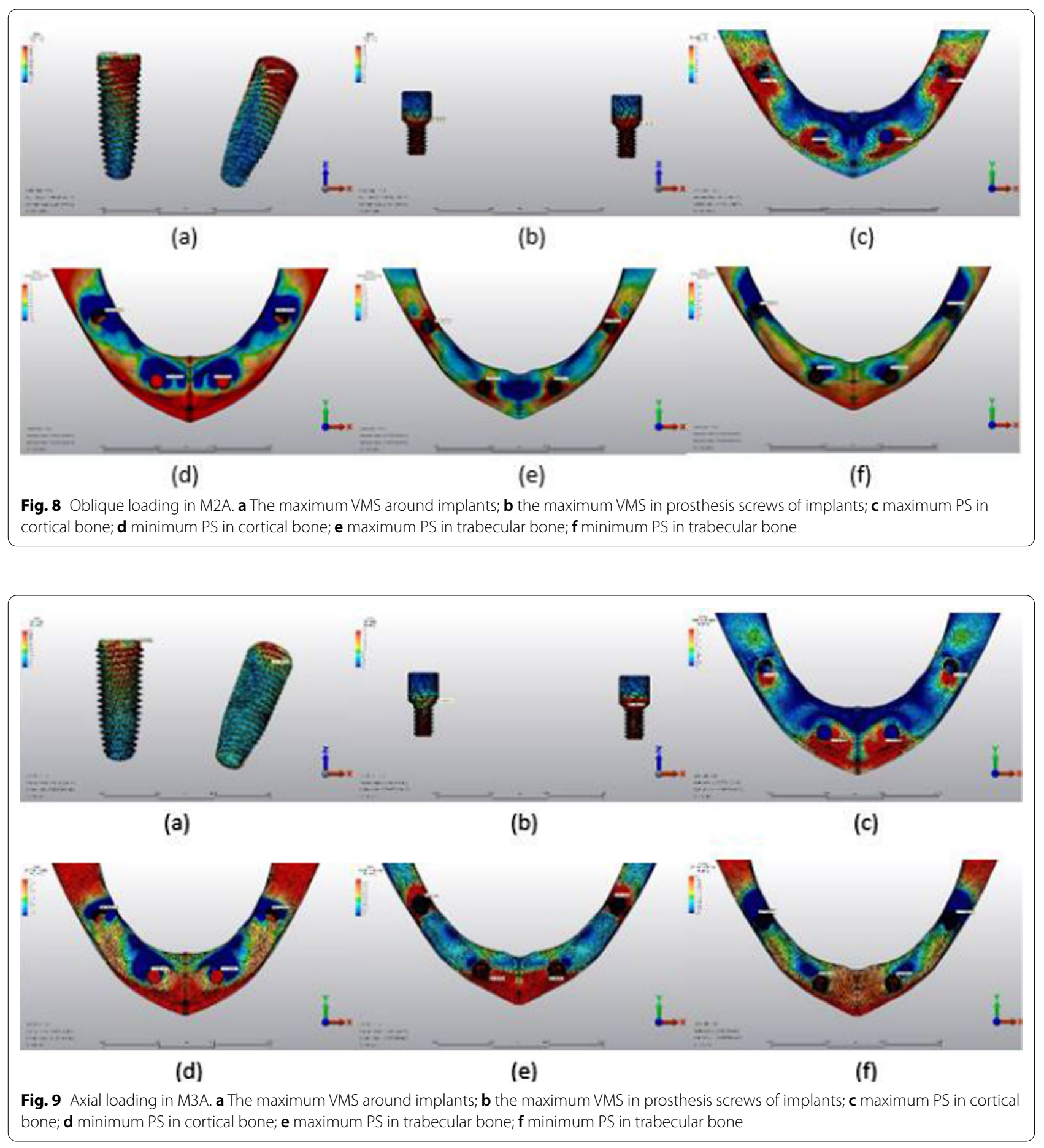

and minimum PS values in the cortical bone around anterior and posterior implants under oblique loading were also observed in the M1B model.

Under axial loads, the lowest maximum PS in the cortical bone around anterior implants and the lowest minimum PS in the cortical bone around posterior implants were observed in the M1A model. The lowest minimum PS in the cortical bone around anterior implants and the lowest maximum PS in the cortical bone around posterior implants were observed in the M3A model. Under oblique loads, the lowest maximum and minimum PS in the cortical bone around anterior 

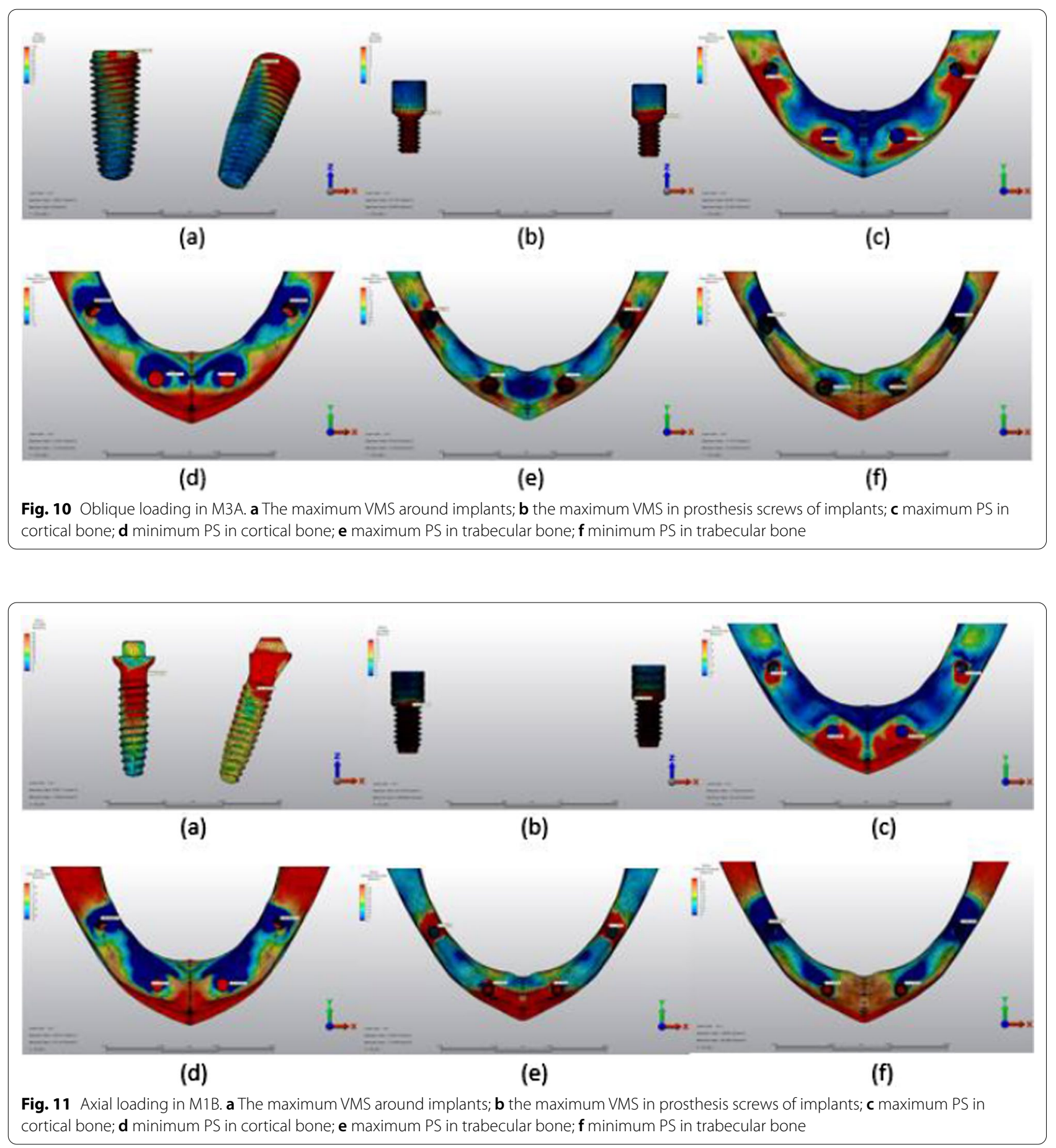

and posterior implants were observed in the M3A model (Table 5).

\section{Assessment of maximum-minimum PS rates in trabecular bone}

Under axial loads, the highest minimum PS values in the trabecular bone were observed around anterior implants in the M3B model and posterior implants in the M1B model. The highest minimum PS values in the trabecular bone around posterior implants were observed in the M3A model, and the highest maximum PS values in the M3B model. Under oblique loads, the highest maximum and minimum PS in the trabecular 

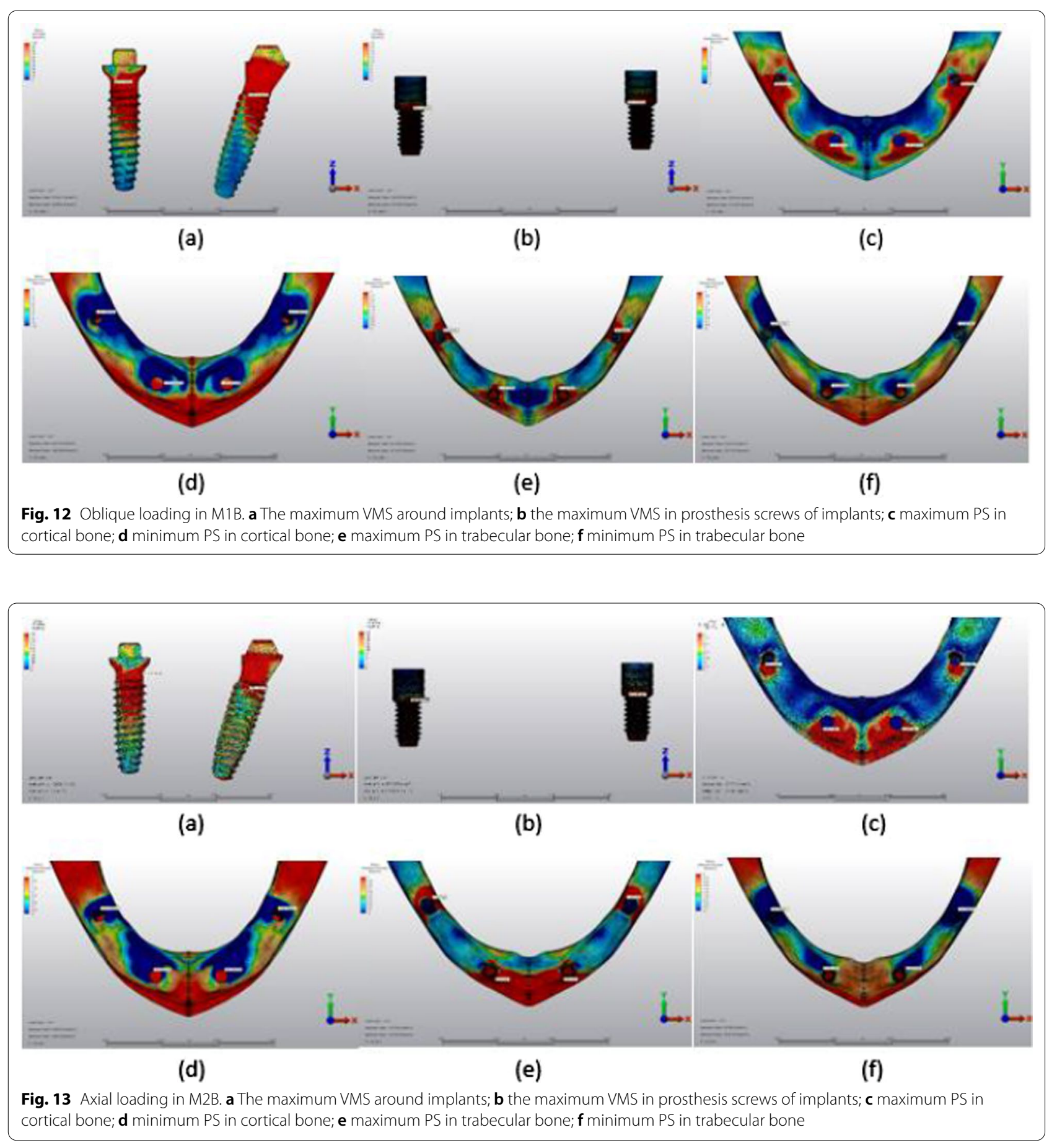

bone around anterior implants were observed in the M1B model and posterior implants in the M3B model.

Axial loading of anterior implants revealed the lowest maximum PS in the trabecular bone in the M2A model and the lowest minimum PS in the M3A model. The lowest maximum and minimum PS in the trabecular bone around posterior implants were observed in the M1B model. Under oblique loads, the lowest maximum PS values were observed in the trabecular bone around anterior implants in the M3A model, and the lowest minimum PS values in the M1A model. The lowest maximum and minimum PS in the trabecular bone around posterior implants were observed in the M1B model (Table 6). 


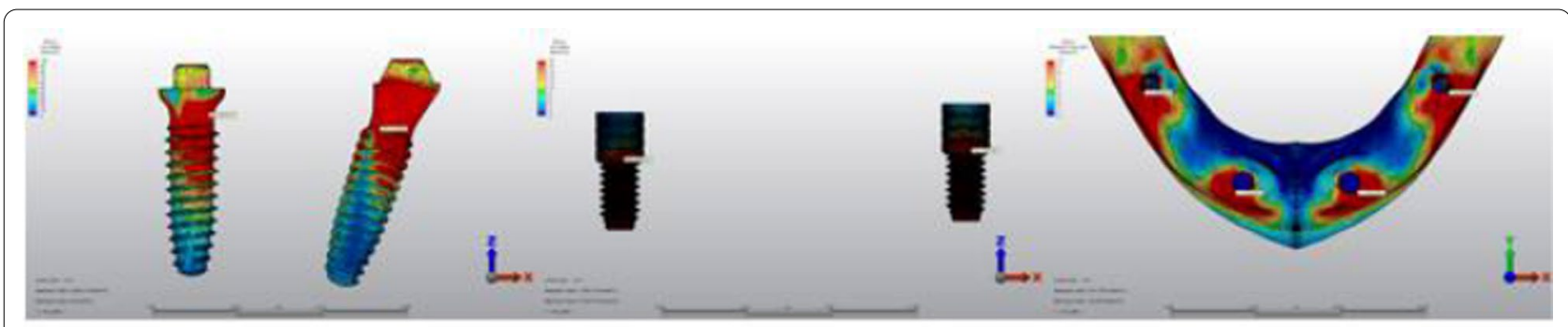

(a)

(b)

(c)

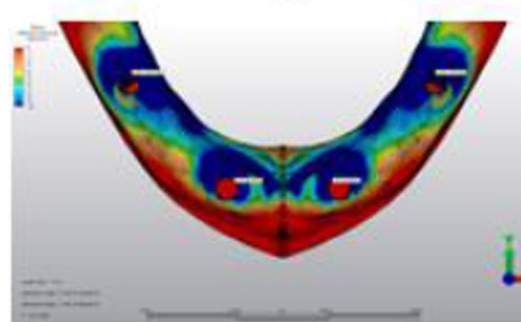

(d)

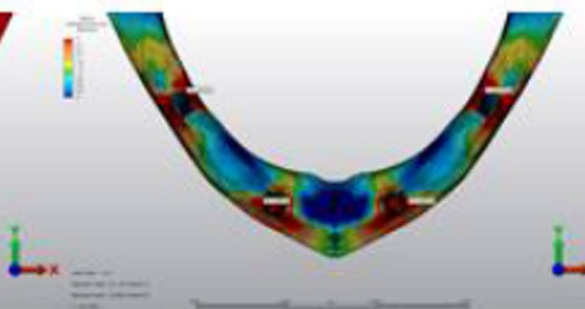

(e)

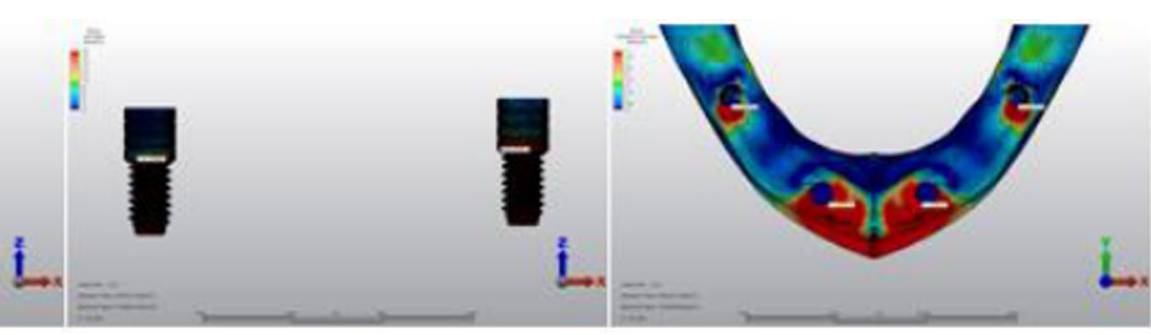

(c) (a)

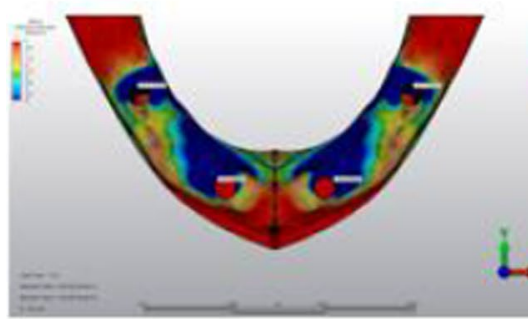

(d)

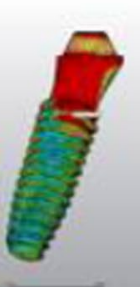

(b)

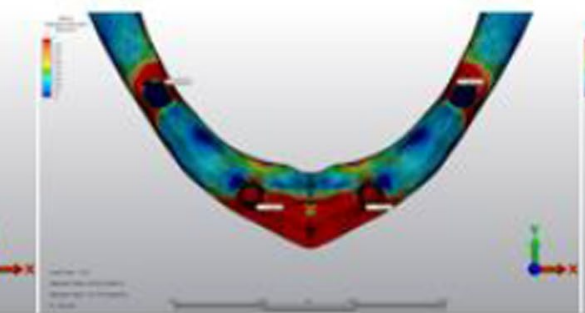

(e)

(f)

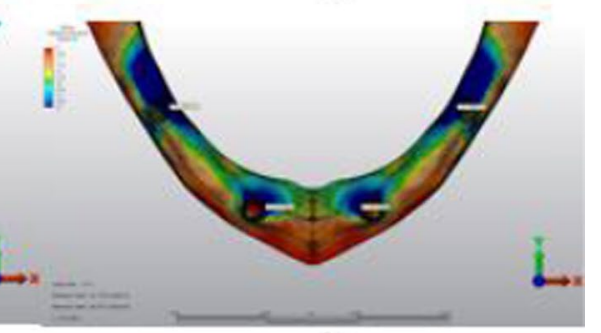

Fig. 14 Oblique loading in M2B. a The maximum VMS around implants; $\mathbf{b}$ the maximum VMS in prosthesis screws of implants; $\mathbf{c}$ maximum PS in cortical bone; $\mathbf{d}$ minimum PS in cortical bone; e maximum PS in trabecular bone; $\mathbf{f}$ minimum PS in trabecular bone

Fig. 15 Axial loading in M3B. a The maximum VMS around implants; $\mathbf{b}$ the maximum VMS in prosthesis screws of implants; $\mathbf{c}$ maximum PS in cortical bone; d minimum PS in cortical bone; e maximum PS in trabecular bone; f minimum PS in trabecular bone

\section{Discussion}

Currently, dental implants are a popular treatment option for the rehabilitation of edentulous patients. Moreover, treatment procedures such as the all-on-four concept that use fewer implants with minimally invasive techniques have gained popularity. In monoblock implant applications, the risk of delay in wound healing is high in individuals with systemic disease, heavy smokers and periodontal disease because the implant is not healed off [13]. However, monoblock dental implants considered as a new system in the all-on-four dental implant procedure can prevent peri-implantitis due to microleakage in angled multiunit abutment-implant connection systems and screw loosening due to micro-movements [14, 


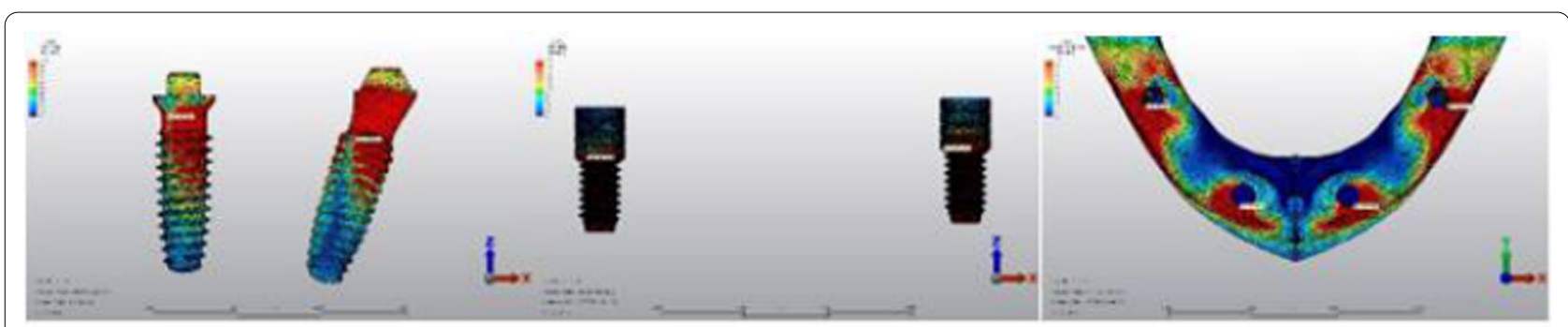

(a)

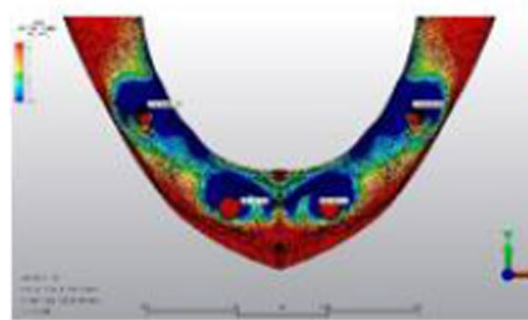

(d) (b)

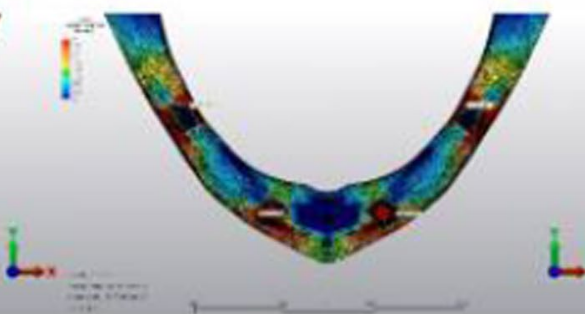

(e) (c)

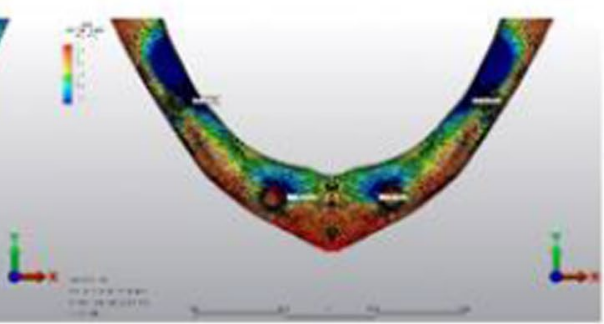

(f)

Fig. 16 Oblique loading in M3B. a The maximum VMS around implants; $\mathbf{b}$ the maximum VMS in prosthesis screws of implants; $\mathbf{c}$ maximum PS in cortical bone; $\mathbf{d}$ minimum PS in cortical bone; e maximum PS in trabecular bone; $\mathbf{f}$ minimum PS in trabecular bone

15]. A systematic review by Mishra et al.[16] reported the presence of microleakage in all multiunit abutments, although the amount of leakage varied according to the torque values applied in the multiunit abutment-implant connection interface with different connection types.

Several studies in the literature suggest that the safe cantilever length is $10 \mathrm{~mm}$ when evaluated in terms of stress distribution in fixed prosthesis supported by four implants [17]. Bellini et al.[18] reported that cantilever lengths from 5 to $15 \mathrm{~mm}$ lead to increase a 33\% stress accumulation at the bone and increase the risk of implant failure. However, Malhotra et al. [19] stated that there was no significant difference between 4 and $12 \mathrm{~mm}$ cantilever lengths in this concept. Therefore, we determined the cantilever length as $10 \mathrm{~mm}$ in the design of the models in this study.

Dental implant diameter is important when considering stress distribution against chewing forces. Several studies suggest that increased implant diameter reduces stress values in implants [20-22]. These observations differ from the results obtained in some group A models in this study; however, they were consistent with the findings in the B group models. A comparison between both groups to assess stress accumulation in implants showed that stress values in the B group models were higher than those in the A group. The factor in the conflict between the stress values in implants in the A group with the literature may be a limitation of the study. Because chewing forces are cyclic forces. In this study, finite element analysis is limited in fully reflecting clinical conditions as it allows static forces to be measured. Therefore, this study is a preliminary study and should be confirmed by clinical studies.

There are two types of modeling; parametric surface modelling (surface first approach) and freeform mesh modelling (mesh first approach), with each having its own pros and cons in the validation of finite element models. In the surface first approach, although it has the advantages of changing the mesh detail in the later stages and the application of load and boundary conditions to the surfaces is very easy, it has disadvantages such as the difficulty of modeling complex organic shapes and the difficulty of solid lattice organic shapes in the optimum number of elements. In the mesh first approach, the modeler must estimate and decide the number of mesh needed before modeling. It is difficult to change the mesh detail size in the late stages. Also, since there are no surfaces, the user cannot select surfaces to apply boundary conditions. If the user requests to perform a surface loading operation, the user will need to select nodes as the boundary condition points. However, this approach has the advantages of making it easier to model complex geometries as freehand tools are very strong in meshbased modelers, and in the first mesh approach, the modeler can manually adjust the level of detail to easily reach the optimum number of elements. So, we have used mesh first approach to get highly detailed and realistic organic $3 \mathrm{~d}$ models that cannot be achieved by parametric surface modeling. The software that we have used can import the mesh models (.stl files) and perform solid modelling 
and analysis. By this way, we gain the advantage of working on highly realistic $3 \mathrm{~d}$ models in the cost of losing the ability to find the convergence point. However, since our models are highly detailed and the number of meshed and nodes is far beyond any possible convergence point, we assume that we get rid of that disadvantage of the mesh first approach method.

In multiunit abutment-implant connection systems, abutment screw loosening may occur due to prosthetic loads and lead to mechanical complications such as screw fracture [23]. Ji-Hyeon et al. [24] reported that the stress in posterior implant screws was higher than that in anterior implant screws when stress distributions in prosthetic screws were examined in the all-on-four concept. In this study, the stress values in posterior implant screws were higher than those in anterior implant screws. However, the stress values observed in prosthetic screws in the B group models were higher than those in the A group models. AlHomidhi et al. [25] simulated a 5-year chewing function with a chewing simulator in a comparison study of screw-retained and multiunit screw-retained abutments. As a result, they stated that multiunit screwretained abutments are more resistant to occlusal forces. A possible reason could be that in multiunit abutmentimplant connection systems, two screws, one in the abutment-implant connection and the other between the abutment-prosthesis, reduce the occlusal forces by dividing them.

Moraes et al. [26] examined the effects in the cortical bone around dental implants of different diameters under the application of axial and oblique forces. They reported that wide-diameter implants had lower stress values in the cortical bone than regular diameter implants and axial forces compared to oblique forces. In all models of this study, stress accumulation in the cortical bone under oblique loads was higher than that under axial loads. Moreover, the highest stress value in the cortical bone under oblique loading was seen in the M1B model that had the narrowest implant diameter $(3.5 \mathrm{~mm})$ in group $B$. This finding suggests that the stress distribution depends on implant diameters. However, a comparison between both groups showed that stress values in the cortical bone were higher in group B under axial and oblique loading. In the stress assessment of the trabecular bone, the highest stress was observed in the narrowest implant in group B. Raaj et al. [27], in a comparison study of the stress values of implants of two different diameters, reported that the highest stress values were in the trabecular bone around the $3.5 \mathrm{~mm}$ diameter implant and the lowest in the trabecular bone around the $4.3 \mathrm{~mm}$ diameter implant. In this study, stress values in the trabecular bone around the implant of $3.5 \mathrm{~mm}$ and $4 \mathrm{~mm}$ diameters were found to be similar. However, in most stress values of the trabecular bone around the $4.5 \mathrm{~mm}$ diameter implants were found to be higher than the trabecular bone stress values around the $3.5 \mathrm{~mm}$ and $4 \mathrm{~mm}$ diameter implant. With these findings, it was concluded that the periodic increase in implant diameter is not directly proportional to the decrease in stress in the trabecular bone around the implant.

A new tilted monoblock dental implant system may be an alternative in the all-on-four concept to prevent possible infection in the multiunit abutment-implant connection. However, this system needs to be developed with further studies to reduce stress and tension values in implants, implant components, and bone. Moreover, this study should be supported by other in vitro and in vivo studies.

\section{Conclusions}

In axial and oblique loads, Von Mises stress values in implants, cortical and trabecular bone around the implants and prosthetic screw of the implant in group $\mathrm{B}$ are higher than in group $\mathrm{A}$.

\section{Abbreviations}

FEM: Finite element method; 3-D: Three-dimension; GPa: Gigapascal; mm: Milimeter; N: Newton; GB: Gigabyte; GHz: Gigahertz; M1A: Model-1A; M2A: Model-2A; M3A: Model-3A; M1B: Model-1B; M2B: Model-2B; M3B: Model-3B; VMS: Von Mises stress; MPa: Megapascal; PS: Principal stress.

\section{Acknowledgements}

Not applicable.

\section{Authors' contributions}

ÖÖZ read, collected data, analyzed statistically and wrote the manuscript. AP revised, searched the additional data and corrected the entire article. Both authors read and approved the final manuscript.

\section{Funding}

Not applicable.

\section{Availability of data and materials}

The datasets used and/or analysed during the current study are available from the corresponding author on reasonable request.

\section{Declarations}

Ethics approval and consent to participate

Not applicable.

Consent for publication

Not applicable.

\section{Competing interests}

The authors declare that they have no competing interests.

\section{Author details}

${ }^{1}$ Department of Oral and Maxillofacial Surgery, Faculty of Dentistry, Istanbul Gelisim University, Istanbul, Turkey. ${ }^{2}$ Department of Periodontology, Private Primadent Oral, Dental Health and Implantology Center, Ankara, Turkey. 
Received: 12 October 2020 Accepted: 13 December 2021

Published online: 16 December 2021

\section{References}

1. Lee DJ, Saponaro PC. Management of edentulous patients. Dent Clin North Am. 2019;63(2):249-61.

2. Chiapasco M, Zaniboni M. Methods to treat the edentulous posterior maxilla: implants with sinus grafting. J Oral Maxillofac Surg. 2009:67(4):867-71.

3. Bhering CL, Mesquita MF, Kemmoku DT, Noritomi PY, Consani RL, Barao VA. Comparison between all-on-four and all-on-six treatment concepts and framework material on stress distribution in atrophic maxilla: a prototyping guided 3D-FEA study. Mater Sci Eng C Mater Biol Appl. 2016;69:715-25.

4. Schwartz-Arad D, Herzberg R, Dolev E. The prevalence of surgical complications of the sinus graft procedure and their impact on implant survival. J Periodontol. 2004;75(4):511-6.

5. Eliasson A, Palmqvist S, Svenson B, Sondell K. Five-year results with fixed complete-arch mandibular prostheses supported by 4 implants. Int J Oral Maxillofac Implants. 2000;15:505-10.

6. Papaspyridakos P, De Souza A, Vazouras K, Gholami H, Pagni S, Weber HP. Survival rates of short dental implants $(<6 \mathrm{~mm}$ ) compared with implants longer than $6 \mathrm{~mm}$ in posterior jaw areas: a meta-analysis. Clin Oral Implants Res. 2018;29(Suppl 16):8-20.

7. Saleh Saber F, Ghasemi S, Koodaryan R, Babaloo A, Abolfazli N. The comparison of stress distribution with different implant numbers and inclination angles in all-on-four and conventional methods in maxilla: a finite element analysis. J Dent Res Dent Clin Dent Prospects. 2015;9(4):246-53.

8. Tallarico M, Canullo L, Caneva M, Ozcan M. Microbial colonization at the implant-abutment interface and its possible influence on periimplantitis: a systematic review and meta-analysis. J Prosthodont Res. 2017;61:233-41

9. Sasada Y, Cochran DL. Implant-abutment connections: a review of biologic consequences and peri-implantitis implications. Int J Oral Maxillofac Implants. 2017;32:1296-307.

10. Liaw K, Delfini RH, Abrahams JJ. Dental implant complications. Semin Ultrasound CT MR. 2015;36(5):427-33.

11. Özdal Zincir Ö, Karapinar G, Ünür M, Katiboğlu AB. How do differences of dental implants' internal connection systems affect stress distribution? A 3-dimensional finite element analysis. Balk J Dent Med. 2019:23:126-31.

12. van Steenberghe D, Jacobs R, Desnyder M, Maffei G, Quirynen M. The relative impact of local and endogenous patient-related factors on implant failure up to the abutment stage. Clin Oral Implants Res. 2002:13(6):617-22.

13. Ellakwa A, Raj T, Deeb S, Ronaghi G, Martin FE, Klineberg I. Influence of implant abutment angulations on the fracture resistance of overlaying CAM-milled zirconia single crowns. Aust Dent J. 2011;56:132-40.

14. Rismanchian M, Hatami M, Badrian H, Khalighinejad N, Goroohi H. Evaluation of microgap size and microbial leakage in the connection area of 4 abutments with Straumann (ITI) implant. J Oral Implantol. 2012;38(6):677-85.

15. Simon RL. Single implant-supported molar and premolar crowns: a tenyear retrospective clinical report. J Prosthet Dent. 2003;90:517-21.

16. Mishra SK, Chowdhary R, Kumari S. Microleakage at the different implant abutment interface: a systematic review. J Clin Diagn Res. 2017;11(6):ZE10-5.

17. Correa S, Ivancik J, Isaza JF, Naranjo M. Evaluation of the structural behavior of three and four implant-supported fixed prosthetic restorations by finite element analysis. J Prosthodont Res. 2012;56(2):110-9.

18. Bellini CM, Romeo D, Galbusera F, et al. Comparison of tilted versus nontilted implant-supported prosthetic designs for the restora-tion of the edentulous mandible: a biomechanical study. Int J Oral Maxillofac Implants. 2009;24:511-7.

19. Malhotra AO, Padmanabhan TV, Mohamed K, Natarajan S, Elavia U. Load transfer in tilted implants with varying cantilever lengths in an all-on-four situation. Aust Dent J. 2012:57(4):440-5.

20. Eazhil R, Swaminathan SV, Gunaseelan M, Kannan GV, Alagesan C. Impact of implant diameter and length on stress distribution in osseointegrated implants: a 3D FEA study. J Int Soc Prev Community Dent. 2016;6(6):590-6.

21. Kilic E, Doganay O. Evaluation of stress in tilted implant concept with variable diameters in the atrophic mandible: three-dimensional finite element analysis. J Oral Implantol. 2020;46(1):19-26.

22. Robau-Porrua A, Pérez-Rodríguez Y, Soris-Rodríguez LM, Pérez-Acosta O, González JE. The effect of diameter, length and elastic modulus of a dental implant on stress and strain levels in peri-implant bone: a 3D finite element analysis. Biomed Mater Eng. 2020;30:541-58.

23. Huang Y, Wang J. Mechanism of and factors associated with the loosening of the implant abutment screw: a review. J Esthet Restor Dent. 2019;31(4):338-45

24. Oh JH, Kim YS, Lim JY, Choi BH. Stress distribution on the prosthetic screws in the all-on-4 concept: a three-dimensional finite element analysis. J Oral Implantol. 2020;46(1):3-12.

25. AlHomidhi M, Alqahtani F. Evaluation of fracture load of cement-, screw-, and multiscrew-retained abutments for implant-supported fixed partial dentures. Int J Oral Maxillofac Implants. 2021;36(1):55-8.

26. Moraes SLD, Verri FR, Santiago JF Jr, Almeida DAF, Lemos CAA, Gomes $J M L$, et al. Three-dimensional finite element analysis of varying diameter and connection type in implants with high crown-implant ratio. Braz Dent J. 2018;29(1):36-42.

27. Raaj G, Manimaran P, Kumar CD, Sadan DS, Abirami M. Comparative evaluation of implant designs: influence of diameter, length, and taper on stress and strain in the mandibular segment-a three-dimensional finite element analysis. J Pharm Bioallied Sci. 2019;11(Suppl 2):S347-54.

\section{Publisher's Note}

Springer Nature remains neutral with regard to jurisdictional claims in published maps and institutional affiliations.
Ready to submit your research? Choose BMC and benefit from:

- fast, convenient online submission

- thorough peer review by experienced researchers in your field

- rapid publication on acceptance

- support for research data, including large and complex data types

- gold Open Access which fosters wider collaboration and increased citations

- maximum visibility for your research: over $100 \mathrm{M}$ website views per year

At BMC, research is always in progress.

Learn more biomedcentral.com/submissions 